\title{
Accuracy and Sensitivity of Parkinsonian Disorder Diagnoses in Two Swedish National Health Registers
}

\author{
Adina L. Feldman ${ }^{a} \quad$ Anna L.V. Johansson ${ }^{a} \quad$ Margaret Gatz $^{a}$ e $\quad$ Måns Flensburg ${ }^{c}$ \\ Giselle M. Petzinger ${ }^{f}$ Håkan Widner ${ }^{d}$ Mark F. Lew ${ }^{f}$ Nancy L. Pedersen ${ }^{a}$ e \\ Karin Wirdefeldt ${ }^{a, b}$ \\ ${ }^{a}$ Department of Medical Epidemiology and Biostatistics, ${ }^{b}$ Department of Clinical Neuroscience, Karolinska \\ Institutet, 'Section for Traffic Medicine, Department of Geriatrics, Karolinska University Hospital Huddinge, \\ Stockholm, and dSection for Neurology, Department of Clinical Sciences, Lund University, Skåne University \\ Hospital, Lund, Sweden; ${ }^{e}$ Department of Psychology, and ${ }^{\mathrm{f} D e p a r t m e n t}$ of Neurology, University of Southern \\ California, Los Angeles, Calif., USA
}

\section{Key Words}

Epidemiological methods • Parkinson disease •

Parkinsonian disorders $\cdot$ Registries $\cdot$ Validation studies

\begin{abstract}
Background: Swedish population-based national health registers are widely used data sources in epidemiological research. Register-based diagnoses of Parkinson's disease have not been validated against clinical information. Methods: Parkinson's disease (PD) and other parkinsonian disorder diagnoses were ascertained in two registers, i.e. the National Patient Register (NPR) and the Cause of Death Register (CDR). Diagnoses were validated in terms of accuracy (positive predictive value) and sensitivity against data from a population-based study of PD in 1998-2004 that screened more than 35,000 persons and identified 194 cases of parkinsonian disorders including 132 PD cases (the gold standard for the purposes of this study). Results: Accuracy for any parkinsonian disorder diagnoses was $88.0 \%$ in the NPR and $94.4 \%$ in the CDR. Accuracy of PD diagnoses was $70.8 \%$ in the NPR
\end{abstract}

and $66.7 \%$ in the CDR. Misclassification between differential parkinsonian diagnoses was common. The accuracy of PD diagnoses in the NPR improved to $83.0 \%$ by restricting the definition to primary diagnoses only. The sensitivity of PD diagnoses in the NPR and CDR combined was $83.1 \%$, with a mean time to detection of 6.9 years. Conclusions: Population-based national health registers are valid data sources in epidemiological studies of PD or parkinsonian disorder etiology but are less suitable in studies of incidence or prevalence.

Copyright $\odot 2012$ S. Karger AG, Basel

\section{Introduction}

Parkinson's disease (PD) is a progressive and severely disabling neurodegenerative movement disorder and the most common cause of parkinsonian symptoms (parkinsonism), characterized by tremor, bradykinesia and rigidity. Other parkinsonian disorders are secondary (such as cerebrovascular parkinsonism) or atypical (such as

\section{KARGER}

Fax +4161306 1234

E-Mail karger@karger.ch

www.karger.com (c) 2012 S. Karger AG, Basel

$0251-5350 / 12 / 0383-0186 \$ 38.00 / 0$

Accessible online at:

www.karger.com/ned
Adina L. Feldman

Karolinska Institutet, Department of Medical Epidemiology and Biostatistics PO Box 281

SE-171 77 Stockholm (Sweden)

Tel. +46 852482 313, E-Mail Adina.feldman@ki.se 
progressive supranuclear palsy or Lewy body disease). In the present study, 'parkinsonian disorders' refers to PD and all other parkinsonian disorders together. The etiology of parkinsonian disorders is complex, and the causative factors are largely unknown [1]. Diagnoses are primarily clinical as there are no diagnostic biomarkers. Population-based health registers are potentially great assets in the field of PD research.

Swedish national health registers, in particular the National Patient Register (NPR) and the Cause of Death Register (CDR), are frequently used as sources of health data in epidemiological research. The NPR and CDR are population based, with possible follow-up approaching 50 years, making them very useful as secondary data sources [2]. A recent review found that for many diseases, the accuracy of the NPR, which registers inpatient hospital admissions, ranged from 85 to 95\% [3]. However, register-based diagnoses of parkinsonian disorders have not been validated against clinical information. For example, we do not know how many cases may be missed or whether there is misclassification between differential diagnoses of parkinsonian disorders in the registers. Due to differences between diseases in general with regard to diagnosis, the availability of biomarkers, severity, comorbidity, age distribution, hospitalization and mortality risk, the accuracy and sensitivity of register diagnoses must be investigated separately for each disease. The aim of this study was to validate diagnoses of parkinsonian disorders and PD in particular in the NPR and CDR. As the gold standard, we used a population-based study of PD and other parkinsonian disorders in twins [4] in which diagnoses were assigned through screening and clinical workup of more than 35,000 individuals.

\section{Methods}

\section{Study Population}

The Screening Across the Lifespan Twin study (SALT) [5] was an endeavor to screen all twins living in Sweden and born before 1958 for common complex diseases between 1998 and 2002. Twins older than 50 years at the screening telephone interview ( $n=49,814$ ) were eligible to be included in a study of PD that has been described in detail previously [4]. The SALT screening was the first of three phases in the study. The second and third phases were a follow-up telephone interview of suspected cases and subsequent clinical workup taking place in 2002-2004. Briefly, in SALT, the twins (or, if unable to participate themselves, a proxy) were asked questions specific to parkinsonian symptoms and the use of antiparkinson medications and direct questions regarding whether they had PD. This screening procedure has been validated and shown to be highly sensitive [6]. In total, 36,197 twins (73\%) were screened. Twins suspected of PD in the first screening
( $\mathrm{n}=787$ ) were contacted again in a second screening interview (phase II) with the purpose of excluding from further follow-up those with suspected PD who reported symptoms due to diseases other than PD. The second screening interview was conducted by telephone by research nurses and included additional questions about parkinsonian symptoms and diagnosis, other diseases and medications. If the twins remained suspects after the second screening, they were invited to a clinical workup (phase III, see below). After excluding twins with an uncertain diagnostic status (i.e. twins who screened positive for PD but were not worked up due to loss to follow-up or refusal to participate in the second screening or clinical phase; $n=476$ ), the final study population included 35,788 twins with available data.

\section{Gold Standard Diagnoses of Parkinsonian Disorders}

Briefly, following two phases of screening, a total of 420 twins participated in the clinical workup (phase III), including $102 \mathrm{co}-$ twins of suspected cases. Twins who self-reported a PD diagnosis in the screening were worked up by review of medical records and telephone interview $(n=195)$. Twins who did not report a PD diagnosis but who were suspected cases based on their responses to the screening questions about symptoms or medications were worked up with a clinical examination in their home, an in-person interview and a review of their medical records $(n=225)$. The Unified Parkinson's Disease Rating Scale [7] was used to evaluate parkinsonian signs and symptoms. Diagnoses of PD were assigned according to the National Institute of Neurological Disorders and Stroke criteria [8] by a study physician together with movement disorder specialists, who independently assigned diagnoses, reviewed cases where there was disagreement and agreed upon final consensus diagnoses. Diagnoses of multiple system atrophy, progressive supranuclear palsy and Lewy body disease were based on previously published criteria [9-11]. Diagnoses of cerebrovascular parkinsonism were based on clinical experience and, where available, computer tomography imaging, in line with clinical practice at that time [12]. In total, 194 cases of parkinsonian disorders, including 132 PD cases, were identified. These cases constituted the gold standard-positive cases in the present study. Non-PD parkinsonian disorders included progressive supranuclear palsy $(n=6)$, multiple system atrophy $(n=3)$, cerebrovascular parkinsonism $(n=32)$, parkinsonism in dementia $(n=$ $5)$, Lewy body disease $(n=11)$ and parkinsonism of unknown cause $(n=5)$. Of all parkinsonian disorder cases, $107(55.2 \%)$ were men. The mean (SD) age at screening was 63.1 (9.7) years for the study population overall and 74.7 (8.8) years for the parkinsonian disorder cases. Age at symptom onset was self-reported or derived from medical records for 185 cases (94.4\%). Mean (SD) age at onset was 68.7 (11.1) years, and mean (SD) disease duration at screening was 6.3 (6.6) years. All procedures were performed according to the Declaration of Helsinki, and the project was approved by the Regional Ethical Review Board in Stockholm and the University of Southern California Institutional Review Board.

\section{The NPR and CDR}

The SALT study population was linked to the NPR and CDR by the 10-digit personal identification number assigned to all Swedish residents [13].

Sweden has a decentralized unified health care system with universal coverage that ensures equal access to inpatient hospital care. The NPR [14] includes information about hospitalizations 
Table 1. ICD codes used to identify PD and other parkinsonian disorders in the health registers

\begin{tabular}{lll}
\hline ICD version (follow-up period) & Code & Description \\
\hline ICD-7 (1961-1967) & $350^{1}$ & PD (paralysis agitans) \\
\hline ICD-8 (1968-1986) & $342.00^{1}$ & PD \\
& 342.08 & other defined parkinsonism \\
& 342.09 & unspecified parkinsonism \\
\hline ICD-9 (1987-1996) & $332.0^{1}$ & PD \\
& 333.0 & other degenerative diseases of the basal ganglia \\
\hline ICD-10 (1997-2009) & G201 & PD \\
& G21.4 & vascular parkinsonism \\
& G21.8 & other defined secondary parkinsonism \\
& G21.9 & unspecified secondary parkinsonism \\
& G23.1 & progressive supranuclear ophthalmoplegia \\
& G23.2 & unspecified degenerative disease of basal ganglia \\
& G25.9 & unspecified extrapyramidal and movement disorder
\end{tabular}

${ }^{1}$ Codes used to identify PD cases. All other codes refer to non-PD parkinsonian disorders.

recorded at discharge. Each record states admission and discharge dates, hospital department and the primary and up to 7 contributory diagnoses coded according to the Swedish versions of the current edition (at the time of diagnosis) of the International Classification of Diseases (ICD). The NPR started in 1964 in 6 counties (of a total of 26 Swedish counties). The register has had full national coverage since 1987. In the present study, the NPR was available from 1964 to 2009.

The CDR [15] contains information from death records, including underlying and up to 20 contributory causes of death coded according to the current edition (at the time of death) of the ICD. The CDR has had complete national coverage since 1961 and was available in the present study until the end of 2008 .

To identify cases of parkinsonian disorders in the NPR and CDR, we used comprehensive definitions that included all primary and contributory diagnoses in the NPR and all underlying and contributory causes of death in the CDR. We also explored four separate ways of restricting the definition of $\mathrm{PD}$ in the registers, as follows: (1) by excluding register cases who, at any point, had had a non-PD parkinsonian disorder diagnosis (e.g. vascular parkinsonism) in the NPR in addition to a PD diagnosis; (2) by using primary diagnoses only in the NPR or underlying causes of death only in the CDR; (3) by using diagnoses (primary or contributory) from neurological, neurosurgical and geriatric departments only in the NPR, and (4) by only including register cases with at least 2 hospital admissions due to PD (as a primary or contributory diagnosis). ICD codes used to identify parkinsonian disorders are described in table 1.

\section{Statistical Analysis}

As primary validity measures, we estimated the positive predictive value (PPV) and sensitivity, and as secondary validity measures, specificity and the negative predictive value (NPV). All validity measures were calculated for two outcomes, i.e. (1) any parkinsonian disorder and (2) PD. The accuracy of positive register diagnoses was determined by PPV, i.e. the probability of positive register cases being confirmed by the gold standard (truepositive register cases divided by true plus false-positive register cases). The ability of the registers to detect gold standard-positive cases was determined by sensitivity, i.e. the probability of gold standard-positive cases ever appearing in the register with a diagnosis (true-positive register cases divided by true-positive plus false-negative register cases). The ability of the register to 'detect' gold standard non-cases was determined by specificity, i.e. the probability of gold standard non-cases accurately not being given any diagnosis in the register (true-negative register cases divided by true-negative plus false-positive register cases). The accuracy of negative register diagnoses compared to the gold standard was determined by NPV, i.e. the probability of study persons without a diagnosis in the register being confirmed as non-cases by the gold standard (true-negative register cases divided by true plus false-negative register cases). Clopper-Pearson exact confidence limits for proportions [16] were used to construct 95\% confidence intervals (CIs) for the validity estimates. Statistical analyses were performed using SAS version 9.2 (SAS Institute Inc., Cary, N.C., USA).

As the index date for each participant (the date at which their gold standard-positive or -negative diagnosis status was known), we used the date of initial telephone contact in the SALT screening. For the NPR, PPV, specificity and NPV were estimated for register diagnoses between 1964 and the index date, and sensitivity was estimated for register diagnoses between 1964 and the end of follow-up in 2009. In the CDR, study persons who had no gold standard parkinsonian disorder but who developed a parkinsonian disorder during follow-up and were subsequently detected by the register would be erroneously considered falsepositive cases (while, in fact, they would be true-positive cases). This misclassification would artificially reduce the estimated 
Table 2. Accuracy of parkinsonian disorder diagnoses in the NPR

\begin{tabular}{|c|c|c|c|c|}
\hline & \multicolumn{4}{|c|}{ Accuracy } \\
\hline & $\begin{array}{l}\mathrm{TP} \\
\mathrm{n}\end{array}$ & $\begin{array}{l}\mathrm{FP} \\
\mathrm{n}\end{array}$ & $\begin{array}{l}\text { PPV } \\
\%\end{array}$ & $95 \% \mathrm{CI}$ \\
\hline \multicolumn{5}{|l|}{ Any parkinsonian disorder } \\
\hline All & 66 & 9 & 88.0 & $78.4-94.4$ \\
\hline Men & 31 & 4 & 88.6 & $73.3-96.8$ \\
\hline Women & 35 & 5 & 87.5 & $73.2-95.8$ \\
\hline \multicolumn{5}{|l|}{ Age at 1st register detection } \\
\hline$\leq 64$ years & 18 & 3 & 85.7 & $63.7-97.0$ \\
\hline $65-70$ years & 13 & 2 & 86.7 & $59.5-98.3$ \\
\hline$\geq 71$ years & 35 & 4 & 89.7 & $75.8-97.1$ \\
\hline \multicolumn{5}{|c|}{ Period of 1 st register detection } \\
\hline ICD-7, -8 (1964-1986) & 4 & 2 & 66.7 & $22.3-95.7$ \\
\hline ICD-9 (1987-1996) & 39 & 3 & 92.9 & $80.5-98.5$ \\
\hline ICD-10 (1997-2002) & 23 & 4 & 85.2 & $66.3-95.8$ \\
\hline \multicolumn{5}{|l|}{$P D$} \\
\hline All & 51 & 21 & 70.8 & $58.9-81.0$ \\
\hline Men & 24 & 10 & 70.6 & $52.5-84.9$ \\
\hline Women & 27 & 11 & 71.1 & $54.1-84.6$ \\
\hline \multicolumn{5}{|l|}{ Age at 1 st register detection } \\
\hline$\leq 64$ years & 17 & 3 & 85.0 & $62.1-96.8$ \\
\hline $65-70$ years & 11 & 3 & 78.6 & $49.2-95.3$ \\
\hline$\geq 71$ years & 23 & 15 & 60.5 & $43.4-76.0$ \\
\hline \multicolumn{5}{|c|}{ Period of 1 st register detection } \\
\hline ICD-7, -8 (1964-1986) & 4 & 2 & 66.7 & $22.3-95.7$ \\
\hline ICD-9 (1987-1996) & 29 & 10 & 74.4 & $57.9-87.0$ \\
\hline ICD-10 (1997-2002) & 18 & 9 & 66.7 & $46.0-83.5$ \\
\hline \multicolumn{5}{|c|}{$\begin{array}{l}\text { Follow-up from } 1964 \text { until screening, by sex, age at detection } \\
\text { and time period of detection. All primary and contributory diag- } \\
\text { noses were used to identify cases in the register. } \mathrm{FP}=\text { False posi- } \\
\text { tive; } \mathrm{TP}=\text { true positive. }\end{array}$} \\
\hline
\end{tabular}

PPV (as well as specificity and NPV). Thus, we could only accurately calculate PPV, specificity and NPV in the CDR over a short follow-up period during which the probability of cases being newly diagnosed was low. We set this limit to 3 years from screening. Sensitivity of the CDR was estimated among deaths occurring between the SALT screening and the end of follow-up in 2008. Combined sensitivity of the NPR and CDR was estimated among all gold standard-positive cases who were followed until their death (until the end of 2009). Dates of death for study persons who died during 2009 (after the end of follow-up in the CDR) were derived from the Swedish Total Population Register. The different follow-up periods used for the primary validity measures in each register are illustrated in online supplementary figure 1 (www.karger.com/doi/10.1159/000336356). The difference in the frequency of PD cases with tremor-dominant disease among those who were and were not detected by the NPR was tested using the $\chi^{2}$ test. Differences in the mean age at onset were tested using a t test.

Validity of Register-Based Parkinson's Disease Diagnoses
Table 3. Sensitivity and time to detection for parkinsonian disorder diagnoses in the NPR

\begin{tabular}{|c|c|c|c|c|c|c|}
\hline & \multicolumn{4}{|c|}{ Sensitivity } & \multicolumn{2}{|c|}{$\begin{array}{l}\text { Time from onset to } \\
\text { detection, years }\end{array}$} \\
\hline & $\begin{array}{l}\mathrm{TP} \\
\mathrm{n}\end{array}$ & $\begin{array}{l}\mathrm{FN} \\
\mathrm{n}\end{array}$ & $\begin{array}{l}\text { sensitiv- } \\
\text { ity, \% }\end{array}$ & 95\% CI & mean $\pm S D$ & range \\
\hline \multicolumn{7}{|c|}{ Any parkinsonian disorder } \\
\hline All & 123 & 71 & 63.4 & $56.2-70.2$ & $6.8 \pm 5.5$ & $0-43$ \\
\hline Men & 65 & 42 & 60.7 & $50.8-70.1$ & $7.2 \pm 6.1$ & $0-43$ \\
\hline Women & 58 & 29 & 66.7 & $55.8-76.4$ & $6.4 \pm 4.7$ & $0-20$ \\
\hline \multicolumn{7}{|l|}{ Age at onset } \\
\hline$\leq 60$ years & 34 & 8 & 81.0 & $65.9-91.4$ & $9.6 \pm 7.8$ & $1-43$ \\
\hline $61-75$ years & 67 & 23 & 74.4 & 64 & $6.4 \pm 3.7$ & $0-15$ \\
\hline$\geq 76$ years & 21 & 32 & 42.9 & $26.5-54.0$ & $3.4 \pm 3.0$ & $0-11$ \\
\hline \multicolumn{7}{|l|}{ Period of onset } \\
\hline 1964-1979 & 8 & 1 & 88.9 & $51.8-99.7$ & $15.0 \pm 13.3$ & $3-43$ \\
\hline 1980-1989 & 32 & 6 & 84.2 & $68.8-94.0$ & $7.0 \pm 4.5$ & $0-16$ \\
\hline 1990-2002 & 82 & 56 & 59.4 & $50.7-67.7$ & $5.9 \pm 3.8$ & $0-14$ \\
\hline \multicolumn{7}{|l|}{$P D$} \\
\hline All & 96 & 36 & 72.7 & $64.3-80.1$ & $7.5 \pm 4.4$ & $0-20$ \\
\hline Men & 51 & 23 & 68.9 & $57.1-79.2$ & $7.6 \pm 4.1$ & $0-16$ \\
\hline Women & 45 & 13 & 77.6 & $64.7-87.5$ & $7.4 \pm 4.6$ & $0-20$ \\
\hline \multicolumn{7}{|l|}{ Age at onset } \\
\hline$\leq 60$ years & 31 & 7 & 81.6 & $65.7-92.3$ & $9.1 \pm 5.2$ & $1-20$ \\
\hline $61-75$ years & 55 & 15 & 78.6 & $67.1-87.5$ & $7.0 \pm 3.7$ & $0-15$ \\
\hline$\geq 76$ years & 9 & 12 & 42.9 & $21.8-66.0$ & $5.3 \pm 3.0$ & $2-11$ \\
\hline \multicolumn{7}{|l|}{ Period of onset } \\
\hline 1964-1979 & 7 & 0 & 100.0 & $59.0-100.0$ & $11.7 \pm 6.8$ & $3-20$ \\
\hline 1980-1989 & 28 & 5 & 84.8 & $68.1-94.9$ & $7.8 \pm 4.5$ & $1-16$ \\
\hline 1990-2002 & 60 & 29 & 67.4 & $56.7-77.0$ & $6.9 \pm 3.7$ & $0-14$ \\
\hline
\end{tabular}

Follow-up 1964-2009, by sex, age at onset and time period of onset. All primary and contributory diagnoses were used to identify cases in the register. $\mathrm{TP}=$ True positive; $\mathrm{FN}=$ false negative.

\section{Results}

\section{National Patient Register}

When considering any parkinsonian disorder overall, NPR diagnoses were confirmed by the gold standard to a high degree (PPV 88.0\%, 95\% CI 78.4-94.4; table 2). PPV was lower for PD diagnoses (70.8\%, 95\% CI 58.9-81.0). Of 21 false-positive PD cases, 13 were gold standard non-PD parkinsonian disorder cases. For any parkinsonian disorder diagnosis, PPV did not differ by sex or age at register detection, but for PD, PPV was higher in those detected in the register at a younger age, although confidence limits overlapped.

The NPR detected many of the gold standard-positive cases with a sensitivity of $63.4 \%$ (95\% CI 56.2-70.2) for any parkinsonian disorder and $72.2 \%$ (95\% CI 64.3-80.1) 
Table 4. Accuracy and sensitivity of restricted PD diagnoses in the NPR and CDR

\begin{tabular}{|c|c|c|c|c|c|c|c|c|}
\hline & \multicolumn{4}{|c|}{ Accuracy } & \multicolumn{4}{|c|}{ Sensitivity } \\
\hline & $\begin{array}{l}\mathrm{TP} \\
\mathrm{n}\end{array}$ & $\begin{array}{l}\mathrm{FP} \\
\mathrm{n}\end{array}$ & $\begin{array}{l}\text { PPV } \\
\%\end{array}$ & $95 \% \mathrm{CI}$ & $\begin{array}{l}\mathrm{TP} \\
\mathrm{n}\end{array}$ & $\begin{array}{l}\text { FN } \\
n\end{array}$ & $\begin{array}{l}\text { sensitivity } \\
\%\end{array}$ & $95 \%$ CI \\
\hline \multicolumn{9}{|l|}{$N P R$} \\
\hline $\begin{array}{l}\text { Excluding non-PD parkinsonian disorder } \\
\text { diagnoses }\end{array}$ & 47 & 20 & 70.1 & $57.7-80.7$ & 88 & 44 & 66.7 & $57.9-74.6$ \\
\hline Primary register diagnoses only & 44 & 9 & 83.0 & $70.2-91.9$ & 66 & 66 & 50.0 & $41.2-58.8$ \\
\hline Specialized departments only ${ }^{1}$ & 20 & 4 & 83.3 & $62.6-95.3$ & 31 & 101 & 23.5 & $16.6-31.7$ \\
\hline$\geq 2$ hospital admissions only & 32 & 10 & 76.2 & $60.6-88.0$ & 80 & 52 & 60.6 & $51.7-69.0$ \\
\hline \multicolumn{9}{|l|}{$C D R$} \\
\hline Underlying causes of death only & 4 & 1 & 80.0 & $28.4-99.5$ & 15 & 62 & 19.5 & $11.3-30.1$ \\
\hline
\end{tabular}

Follow-up in the NPR: 1964 to screening (PPV); 1964 to 2009 (sensitivity). Follow-up in the CDR: 3 years from screening (PPV) or until the end of 2008 (sensitivity). $\mathrm{FN}=$ False negative; $\mathrm{FP}=$ false positive; $\mathrm{TP}=\mathrm{true}$ positive.

${ }^{1}$ Diagnoses in the NPR from neurological, neurosurgical and geriatric departments only.

for PD (table 3). Compared to any parkinsonian disorder diagnosis, the sensitivity of PD diagnoses was higher, indicating that PD cases are somewhat more often detected by the register than non-PD parkinsonian disorder cases. Sensitivity was slightly lower for men compared to women. The median number of hospital admissions with any parkinsonian disorder diagnosis for true-positive register cases was 4 . The overall time difference between symptom onset and first record in the NPR (time to detection) for true-positive register cases was 6.8 years for any parkinsonian disorder and 7.5 years for PD. As expected, the time difference was smaller and sensitivity decreased with older age and later calendar year at symptom onset, as disease duration and time at risk of detection were on average shorter for these cases.

To investigate whether the accuracy of PD diagnoses may be improved when using the NPR, we tried four separate ways of restricting the register definition of $\mathrm{PD}$ (table 4). Firstly, excluding register cases with a non-PD parkinsonian disorder diagnosis in addition to a PD diagnosis did not improve PPV. Secondly, restricting the definition of PD to cases identified with primary PD diagnoses only in the NPR improved the PPV to 83.0\% (95\% CI 70.2-91.9), although sensitivity was reduced to $50 \%$ (95\% CI 41.2-58.8). Thirdly, restricting the definition of PD to cases identified from neurological, neurosurgical and geriatric departments only improved the PPV to 83.3\% (95\% CI 62.6-95.3), although sensitivity was reduced to $23.5 \%$ (95\% CI 16.6-31.7). Fourthly, restricting the definition of PD to only cases with 2 or more hospital admissions with a PD diagnosis improved the PPV to $76.2 \%$ (95\% CI 60.6-88.0), although sensitivity was reduced to $60.6 \%$ (95\% CI 51.7-69.0).

\section{Cause of Death Register}

Mean (SD) follow-up in the CDR was 8.0 (2.1) years for the study population overall and 6.1 (3.2) years for parkinsonian disorder cases. In total, 42 of 194 (21.6\%) parkinsonian disorder cases died within 3 years from screening, and 127 (65.5\%) had died at the end of 2008. PPV in the CDR was $94.4 \%$ (95\% CI 72.7-99.9) for any parkinsonian disorder diagnoses and 66.7\% (95\% CI 41.0-86.7) for PD diagnoses (table 5). When restricting the definition to underlying causes of death only, the PPV for PD diagnoses in the CDR was improved to $80.0 \%$ (95\% CI $28.4-$ 99.5), although the sample size in this subgroup analysis was small (table 4).

Overall, the CDR detected relatively few cases. However, as in the NPR, sensitivity was slightly higher for PD compared to any parkinsonian disorder. Sensitivity was consistently lower in men than in women (table 5). The most common underlying cause of death recorded for PD cases was cardiovascular disease (39.0\% of deaths). This proportion did not differ between men and women. However, among those who died of cardiovascular disease, PD was included as a contributory cause of death for 8 of 12 women (66.6\%) but only for 5 of 18 men (27.7\%).

The combined sensitivity of the NPR and CDR was $70.9 \%$ for any parkinsonian disorder and $83.1 \%$ for PD (calculated among gold standard cases followed until 
Table 5. Accuracy and sensitivity of parkinsonian disorder diagnoses in the CDR

\begin{tabular}{|c|c|c|c|c|c|c|c|c|}
\hline & \multicolumn{4}{|c|}{ Accuracy } & \multicolumn{4}{|c|}{ Sensitivity } \\
\hline & $\begin{array}{l}\mathrm{TP} \\
\mathrm{n}\end{array}$ & & $\begin{array}{c}\text { PPV } \\
\%\end{array}$ & $95 \% \mathrm{CI}$ & $\begin{array}{l}\mathrm{TP} \\
\mathrm{n}\end{array}$ & $\begin{array}{l}\mathrm{FN} \\
\mathrm{n}\end{array}$ & $\begin{array}{l}\text { sensi- } \\
\text { tivity } \\
\%\end{array}$ & $95 \%$ CI \\
\hline \multicolumn{9}{|c|}{ Any parkinsonian disorder } \\
\hline All & 17 & 1 & 94.4 & 72.7-99.9 & 55 & 72 & 43.3 & $34.6-52.4$ \\
\hline Men & 7 & 0 & 100.0 & $59.0-100.0$ & 25 & 48 & 34.2 & $23.5-46.3$ \\
\hline Women & 10 & 1 & 90.9 & $58.7-99.8$ & 30 & 24 & 55.6 & $41.4-69.1$ \\
\hline \multicolumn{9}{|l|}{ Age at death } \\
\hline$\leq 75$ years & 4 & 0 & 100.0 & $39.8-100.0$ & 9 & 12 & 42.9 & $21.8-66.0$ \\
\hline $76-85$ years & s 8 & 1 & 88.9 & $51.8-99.7$ & 28 & 29 & 49.1 & $35.6-62.7$ \\
\hline$\geq 86$ years & 5 & 0 & 100.0 & $47.8-100.0$ & 18 & 31 & 36.7 & $23.4-51.7$ \\
\hline \multicolumn{9}{|l|}{$P D$} \\
\hline All & 12 & & 66.7 & $41.0-86.7$ & 44 & 33 & 57.1 & $45.4-68.4$ \\
\hline Men & 5 & 2 & 71.4 & $29.0-96.3$ & 23 & 24 & 48.9 & $34.1-63.9$ \\
\hline Women & 7 & & 63.6 & $30.8-89.1$ & 21 & 9 & 70.0 & $50.6-85.3$ \\
\hline \multicolumn{9}{|l|}{ Age at death } \\
\hline$\leq 75$ years & 3 & 1 & 75.0 & $19.4-99.4$ & 7 & 5 & 58.3 & $27.7-84.8$ \\
\hline $76-85$ years & s 6 & & 66.7 & $29.9-92.5$ & 26 & 15 & 63.4 & $46.9-77.9$ \\
\hline$\geq 86$ years & 3 & 2 & 60.0 & $14.7-94.7$ & 11 & 13 & 45.8 & $25.6-67.2$ \\
\hline
\end{tabular}

Follow-up for 3 years from screening (PPV) or until the end of 2008 (sensitivity), by sex and age at death. All underlying and contributory causes of death were used to identify cases in the register. $\mathrm{FN}=$ False negative; $\mathrm{FP}=$ false positive; $\mathrm{TP}=$ true positive.

their death). Of the 55 parkinsonian disorder cases detected by the CDR, only 4 (7.2\%) were not previously found by the NPR. The proportion of PD cases with tremor-dominant disease did not differ between those detected by the NPR and those not detected ( 82 and $73 \%$, respectively; $\mathrm{p}=0.31$ ). As expected, mean age at onset was significantly lower among PD cases detected by the NPR (64.4 years, SD 10.0) compared to those not detected (70.5 years, SD 11.1; $\mathrm{p}=0.0041$ ). Sensitivity was $100 \%$ for cases with onset before the age of 50 years.

Specificity and NPV in both the NPR and CDR ranged from 98.5 to $100.0 \%$. The majority of the study population had no gold standard parkinsonian disorder and were accurately true negatives in the registers, as would be expected from low-prevalence disorders.

\section{Discussion}

In this population-based validation study of $\mathrm{PD}$ and any parkinsonian disorder diagnoses in two national health registers, we found that overall, the registers are accurate and sensitive in detecting parkinsonian disorder cases, but that misclassification between PD and non-PD parkinsonian disorders is quite common in both the NPR and CDR. This misclassification goes both ways (PD cases are misclassified as other parkinsonian disorders and, similarly, non-PD parkinsonian disorder cases are misclassified as PD), as indicated by the gold standard nonPD parkinsonian disorder cases found among the NPR false-positive PD cases and the unchanged PPV for PD diagnoses in the NPR when excluding cases with an additional non-PD parkinsonian disorder diagnosis. Misclassification is particularly common with regard to the contributory diagnoses or causes of death, as indicated by the improved PPV when restricting the PD case definition to primary diagnoses or underlying causes of death only. The accuracy of PD diagnoses may be improved by restricting the definition to primary diagnoses in the NPR only, although this comes at a cost of reduced sensitivity. Since PPV declined with age for PD diagnoses in the NPR, misclassification was more common in older ages. Similarly, it has been suggested previously that the commonly observed decline in PD incidence with age is due to underreporting in older ages [17]. Sweden's universal health care coverage ensures that the sensitivity of the NPR is not affected by differential access to inpatient hospital care. We found that clinical presentation (presence of tremor-dominant disease) did not seem to affect disease detection in the NPR. The low sensitivity of the CDR is in line with previous findings of underreporting of PD as a cause of death [18-21].

The strengths of this study include the populationbased setting and gold standard ascertainment of diagnoses that allowed us to estimate sensitivity and PPV as well as specificity and NPV. The majority of previous validation studies of other diseases in the NPR have used patient chart reviews as the gold standard, prohibiting the evaluation of sensitivity, specificity or NPV [3]. A weakness of this study is that the follow-up after the screening was only approximately a decade, which makes the sensitivity estimates of the CDR and NPR incomplete. The low prevalence of parkinsonian disorders unfortunately limits our power in subgroup analyses. Since screening was limited to participants aged 50 or older, young-onset cases may have been missed.

National health registers are valid data sources in epidemiological studies of parkinsonian disorders. However, caution is warranted when using the registers in four situations in particular. Firstly, although estimates of the incidence and prevalence of parkinsonian disorders may be adjusted for misclassification using the validity esti- 
mates reported in this study, we believe the delayed detection together with the reduced sensitivity make the registers less suitable for such studies. Secondly, in survivaltype analyses where PD is an end point, precise incidence dates cannot be derived. Similarly, in studies of prognosis, PD cases cannot be followed from disease onset, since this is unknown. Since the average time period from onset to detection by the NPR differs according to age, it is difficult to attempt to extrapolate age at onset from register data. Thirdly, when the study depends on differential parkinsonian disorder diagnoses, there will be misclassification. We have shown that there are ways to improve the accuracy of PD diagnoses, but not without reducing the sensitivity. Fourthly, if exposures studied in association with $\mathrm{PD}$ are themselves derived from the NPR, the estimates of association may be biased by differential misclassification; i.e. there can be misclassification of disease that is associated with the exposure. However, in studies where exposure is ascertained independently of the national health registers and is unrelated to the sensitivity of detection of parkinsonian disorders, estimates of association will not be biased due to this type of differential misclassification. This is the case because, although sensitivity is reduced, specificity is almost perfect.

The results of this study highlight that in future register-based studies of parkinsonian disorders, the definition of a PD or parkinsonian disorder case should be adapted to the aims of the study. If the aim is to study an association with parkinsonian disorders regardless of the differential diagnosis, the definition can be comprehensive and allow cases identified through primary and contributory diagnoses in the NPR and underlying and contributory causes of death in the CDR. If the aim is to study an association with $\mathrm{PD}$, one approach can be to use only cases identified through primary diagnoses in the NPR.

In 2001, the NPR was extended to include outpatient care in hospital-based clinics (the outpatient register), and in 2005, the national Prescribed Drugs Register was launched. There are also efforts being made in Sweden to establish disease-specific quality registries, including a recent register for $\mathrm{PD}$. We have great hopes that these registers will be valuable population-based data sources for epidemiological studies in the future, especially since they should be able to detect PD cases during their diagnostic workup for PD and may thus prove to be useful when studying incidence and prevalence.

\section{Disclosure Statement}

This work was supported by The Swedish Research Council, The National Institutes of Health (R01 ES010758, R01 AG08724), the Swedish Society for Medical Research, the Swedish Medical Society, the Parkinson Foundation in Sweden and the Karolinska Institutet. The funders of the study had no role in the study design, data collection, data analysis, data interpretation or writing of the report.

Karin Wirdefeldt received a research grant from Syngenta Inc. Håkan Widner received honoraria from $\mathrm{H}$. Lundbeck AB, GSK $\mathrm{AB}$, Medtronic $\mathrm{AB}$ and Biogen Idec $\mathrm{AB}$ and is a stock owner in NeuroVive AB. All other authors have nothing to declare.

\section{References}

1 de Lau LM, Breteler MM: Epidemiology of parkinson's disease. Lancet Neurol 2006;5: 525-535.

2 Sorensen HT, Sabroe S, Olsen J: A framework for evaluation of secondary data sources for epidemiological research. Int J Epidemiol 1996;25:435-442.

3 Ludvigsson JF, Andersson E, Ekbom A, Feychting M, Kim JL, Reuterwall C, Heurgren M, Otterblad Olausson P: External review and validation of the Swedish national inpatient register. BMC Public Health 2011; 11:450.

-4 Wirdefeldt K, Gatz M, Bakaysa SL, Fiske A, Flensburg M, Petzinger GM, Widner H, Lew MF, Welsh M, Pedersen NL: Complete ascertainment of Parkinson disease in the Swedish Twin Registry. Neurobiol Aging 2008;29: 1765-1773.
5 Lichtenstein P, Sullivan PF, Cnattingius S, Gatz M, Johansson S, Carlstrom E, Bjork C, Svartengren M, Wolk A, Klareskog L, de Faire U, Schalling M, Palmgren J, Pedersen NL: The Swedish Twin Registry in the third millennium: an update. Twin Res Hum Genet 2006;9:875-882.

-6 Rocca WA, Maraganore DM, McDonnell SK, Schaid DJ: Validation of a telephone questionnaire for parkinson's disease. J Clin Epidemiol 1998;51:517-523.

7 Fahn S, Elton RL: The UPDRS development committee. Unified parkinson's disease rating scale; in Fahn S, Marsden CD, Calne D, Goldstein M (eds): Recent Developments in Parkinson's Disease. Florham Park, Macmillan Healthcare Information, 1987, vol 2, pp 153-163.

-8 Gelb DJ, Oliver E, Gilman S: Diagnostic criteria for parkinson disease. Arch Neurol 1999;56:33-39.
-9 Gilman S, Low P, Quinn N, Albanese A, BenShlomo Y, Fowler C, Kaufmann H, Klockgether T, Lang A, Lantos P, Litvan I, Mathias C, Oliver E, Robertson D, Schatz I, Wenning $\mathrm{G}$ : Consensus statement on the diagnosis of multiple system atrophy. American Autonomic Society and American Academy of Neurology. Clin Auton Res 1998;8:359-362.

10 Litvan I, Agid Y, Calne D, Campbell G, Dubois B, Duvoisin RC, Goetz CG, Golbe LI, Grafman J, Growdon JH, Hallett M, Jankovic J, Quinn NP, Tolosa E, Zee DS: Clinical research criteria for the diagnosis of progressive supranuclear palsy (Steele-RichardsonOlszewski syndrome): Report of the NINDSSPSP international workshop. Neurology 1996;47:1-9. 
11 McKeith IG, Galasko D, Kosaka K, Perry EK, Dickson DW, Hansen LA, Salmon DP, Lowe J, Mirra SS, Byrne EJ, Lennox G, Quinn NP, Edwardson JA, Ince PG, Bergeron C, Burns A, Miller BL, Lovestone S, Collerton D, Jansen EN, Ballard C, de Vos RA, Wilcock GK, Jellinger KA, Perry RH: Consensus guidelines for the clinical and pathologic diagnosis of dementia with Lewy bodies (DLB): report of the consortium on DLB international workshop. Neurology 1996;47:1113-1124.

12 Winikates J, Jankovic J: Clinical correlates of vascular parkinsonism. Arch Neurol 1999; 56:98-102.

13 Ludvigsson JF, Otterblad-Olausson P, Pettersson BU, Ekbom A: The Swedish personal identity number: possibilities and pitfalls in healthcare and medical research. Eur J Epidemiol 2009;24:659-667.
14 National Board of Health and Welfare: The National Patient Register. http://www.Socialstyrelsen.Se/register/halsodataregister/ patientregistret/inenglish (accessed December 2011).

15 National Board of Health and Welfare: The Cause of Death Register (in Swedish). http:// www.Socialstyrelsen.Se/register/dodsorsaksregistret\# (accessed December 2011).

16 Clopper CJ, Pearson ES: The use of confidence or fiducial limits illustrated in the case of the binomial. Biometrika 1934;26:404413.

17 Bower JH, Maraganore DM, McDonnell SK, Rocca WA: Influence of strict, intermediate, and broad diagnostic criteria on the age- and sex-specific incidence of parkinson's disease. Mov Disord 2000;15:819-825.
8 Beyer MK, Herlofson K, Arsland D, Larsen JP: Causes of death in a community-based study of parkinson's disease. Acta Neurol Scand 2001;103:7-11.

19 Paulson GW, Gill WM: Are death certificates reliable to estimate the incidence of parkinson's disease? Mov Disord 1995; 10: 678.

20 Fall PA, Saleh A, Fredrickson M, Olsson JE, Granerus AK: Survival time, mortality, and cause of death in elderly patients with Parkinson's disease: a 9-year follow-up. Mov Disord 2003;18:1312-1316.

21 Elbaz A, Bower JH, Peterson BJ, Maraganore DM, McDonnell SK, Ahlskog JE, Schaid DJ, Rocca WA: Survival study of Parkinson disease in Olmsted County, Minnesota. Arch Neurol 2003;60:91-96.

\section{Erratum}

In the article 'Can Mortality Data Provide Reliable Indicators for Creutzfeldt-Jakob Disease Surveillance? A Study in France from 2000 to 2008', published as Neuroepidemiology 2011;37:188-192, one of the authors' names was misspelled. The correct name is Albertine Aouba. 